\title{
Erratum to: The Index of Household Financial Condition, Combining Subjective and Objective Indicators: An Appraisal of Italian Households
}

\author{
Piotr Bialowolski • Dorota Weziak-Bialowolska
}

Published online: 31 August 2013

(C) Springer Science+Business Media Dordrecht 2013

\section{Erratum to: Soc Indic Res \\ DOI 10.1007/s11205-013-0401-0}

The following Acknowledgments were missing in the article.

Acknowledgments We would like to thank Polish National Centre of Science for providing funds for the research (Grant no. UMO-2011/01/D/HS4/04051), but also the University of Milan, Department of Economics, Management and Quantitative Methods, where Piotr Bialowolski had a chance to complete the project as a Visiting Researcher.

The online version of the original article can be found under doi:10.1007/s11205-013-0401-0.

P. Bialowolski

Institute of Statistics and Demography, Warsaw School of Economics, U1. Madalinskiego 6/8, 02-513 Warsaw, Poland

e-mail: piotr.bialowolski@gmail.com

P. Bialowolski

Department of Economics, Management and Quantitative Methods, University of Milan, Milan, Italy

D. Weziak-Bialowolska $(\bowtie)$

Econometrics and Applied Statistics Unit, Institute for the Protection and Security of the Citizen, Joint Research Centre, European Commission, Via E. Fermi 2749, TP 361, 21027 Ispra, VA, Italy

e-mail: dorota.bialowolska@gmail.com 